\title{
Grain elevator workers show work-related pulmonary function changes and dose-effect relationships with dust exposure
}

\author{
P COREY, M HUTCHEON, I BRODER, AND S MINTZ \\ From the Gage Research Institute and Department of Medicine, University of Toronto, Toronto, Canada \\ MST 1R4
}

ABSTRACT The purpose of this study was to determine whether grain handlers underwent workrelated changes in their pulmonary function and, if so, to examine the dose-effect relationships with dust exposure. The pulmonary function of grain handlers was measured at the beginning and end of work shifts over a period of one week, during which their exposure to dust was measured daily. The results showed changes indicative of a within-day obstructive change, in addition to a small restrictive defect occurring over the course of a week. Civic outside labourers who were examined as a control group showed a similar within-week obstructive change without any associated restriction of lung volume. The data on the grain handlers were also used to examine the dose-effect relationships of dust exposure, both on baseline pulmonary function and on within-day changes in these measurements. The baseline flow rates of workers who did not wear a mask were found to vary inversely with their average exposure to respirable dust. In addition, the flow rates underwent a within-day decrease that varied directly with their corresponding exposure to respirable dust and was unrelated to mask wearing. The median of the slopes for this relationship indicated that $50 \%$ of the subjects had a decrease of at least $923 \mathrm{ml} / \mathrm{s}$ in the value of their $\dot{V} \max _{50 \% \mathrm{VC}}$ for each $1 \mathrm{mg} / \mathrm{m}^{3}$ increase in the concentration of respirable dust. Nonrespirable dust did not have a measurable effect either on the baseline or the within-day changes in pulmonary function. The acute changes were unaffected by age, duration of employment, or extent of smoking.

The effects on health of employment as a grain handler have been examined mainly in crosssectional studies, ${ }^{1-5}$ which are best suited for the detection of chronic changes. The results obtained have shown a small excess of symptoms of bronchitis and a slight decrease in flow and volume variables of pulmonary function. Only one previous study has inquired into the possible presence of short-term health effects, ${ }^{2}$ and none has dealt with the issue of dose-effect relationships. The purposes of the following studies were to examine the pulmonary function and the dust exposure of grain handlers within shifts and during a week of work and to clarify the nature of any dose-effect relationships found.

\section{Materials and methods}

The data on the grain handlers described in this

Received 24 August 1981

Accepted 27 November 1981 report were obtained in May 1977 on employees of the Saskatchewan Wheat Pool in Thunder Bay. A questionnaire was completed on all subjects, providing details of age, duration of employment, smoking history, and other information. ${ }^{16}$ Workers of varying levels of seniority were selected by the superintendent from all operational areas of the elevator, based on the feasibility of releasing them from their duties at the required times. All workers were otherwise equally eligible, and the agreement for them to participate in the study was obtained through a process of informed consent. A total of 47 grain handlers was examined, representing about $25 \%$ of the staff of one elevator (pool 4).

The tests performed on the grain workers included maximal expiratory flow volume curves obtained at the beginning and end of the 0800 to 1600 work shift on Monday, Wednesday, and Friday of a given week. Also, lung volumes were estimated at the beginning of the work shift on Monday and at the end on Friday. The subjects were asked to 330 
undergo all pulmonary function tests in a given week, and 47 subjects were studied over four weeks. Each subject wore a personal dust monitor for the full shift on all five days of the same week.

During June and July 1977, we also examined 15 civic outside labourers who were members of the divisions of sanitation (11), roads (2), and sewage and water (2). These subjects were providing flow volume curves and lung volume measurements on Monday mornings as one aspect of a large crosssectionai study ${ }^{1}$ and were asked to repeat the same procedure on Friday morning of the same week. No measurements were made of their associated dust exposure.

Maximal expiratory flow volume curves breathing air were carried out with a wedge spirometer equipped with a one-second time marker and a direct writing $\mathrm{X}-\mathrm{Y}$ recorder as described previously. ${ }^{16}$ Replicate curves for a given subject were superimposed, and the manoeuvre was repeated until two tracings were obtained that corresponded within 5\% both for forced vital capacity (FVC) and for flow over the lower $70 \%$ of vital capacity. The best of the two superimposed curves (based on acceptable effort, with the largest VC and flow rate) was used to measure the FVC, the forced expiratory volume in one second $\left(\mathrm{FEV}_{1}\right)$, and flow rates at $50 \%$ and $25 \%$ of the vital capacity ( $\operatorname{Vmax}_{50 \% \mathrm{vC}}$ and $\left.\operatorname{Vmax}_{25 \% \mathrm{vc}}\right)$. The results were expressed in BTPS as a percentage of the age-height predicted values, using the formula of Goldman and Becklake for the FVC, ${ }^{7}$ Morris and associates for the FEV ${ }_{1}{ }^{8}$ and Lapp and Hyatt for the $\dot{\mathrm{V}} \max _{50 \% \mathrm{VC}}$ and $\dot{\mathrm{V}} \max _{25 \% \mathrm{vc}}{ }^{9}$

The lung volumes were measured by the helium dilution method ${ }^{10}$ using a Collins lung analyser, and included the functional residual capacity (FRC), total lung capacity (TLC), and residual volume (RV). These added tests were expressed as a percentage of the values predicted for age and height using the formula of Goldman and Becklake for the FRC, TLC, and RV.?

The dust exposure of the grain workers was monitored using a Bendix super sampler BDX 44 pump and BDX 99 respirable dust collector (Levitt Safety Ltd, Toronto). The pumps were calibrated with a wet test gas meter and were adjusted to entrain 1.7 litres of air per minute. The rotameters were checked at roughly two-hourly intervals during use and the airflow was readjusted as required. The dust collector consisted of a nylon cyclone (Dorr-Oliver, $10 \mathrm{~mm}$ inside diameter) and a cassette containing a mixed cellulose acetate and nitrate filter $37 \mathrm{~mm}$ in diameter and having a pore size of $0.8 \mu \mathrm{m}$ (Millipore, Toronto). The size-selective characteristics of this cyclone have been described. ${ }^{2}$ The filters were weighed to an accuracy of $\pm 0.03 \mathrm{mg}$ and were desiccated in the presence of anhydrous calcium sulphate for 24 hours both before and after use. The weight of the filters did not change appreciably if desiccated for longer. The dust collected in the cyclone was desiccated in the same manner before being weighed. The term respirable dust is applied to particles collected on the filter and non-respirable dust to those in the cyclone. ${ }^{11}$ The dust sampling and gravimetric analysis were performed by staff members of Labour Canada.

Statistical analysis of the pulmonary function data was performed by analysis of variance, $t$ test for paired and unpaired data, and by correlation analysis, using the statistical analysis system package. ${ }^{12}$ The dose-effect relationships were examined using the Mann-Whitney test for independent comparisons and the sign test and the Wilcoxon signedrank tests for paired comparison. ${ }^{13}$ Multivariate relations were estimated by multiple regression analysis. ${ }^{14}$ Changes in pulmonary function between two points in time were always calculated by subtracting the value obtained at the earlier point from the later one, yielding a negative value for a decrease and a positive value for an increase; logarithms of the pre-shift and post-shift pulmonary function variables were also calculated, which allowed proportional changes in lung function over the work shift to be measured.

\section{Results}

The subjects examined in this study were not selected by a randomising procedure. Nevertheless, their characteristics (table 1) were almost identical to those of a more inclusive group of grain handlers and civic workers that we surveyed in a larger epidemiological study conducted in this community in $1977 .{ }^{1}$ The average respirable and non-respirable dust exposure of the grain handlers was respectively 0.9 and $5.7 \mathrm{mg} / \mathrm{m}^{3}$ of air (table 2). The number of subjects represented in the daily means was not constant and thus caution must be used in comparing the dust measurements between different days.

Table 1 Subjects examined

\begin{tabular}{lcc}
\hline & Grain handlers & Civic workers \\
\hline No of subjects & 47 & 15 \\
Age & $40 \pm 13^{*}$ & $40 \pm 15$ \\
Height $(\mathrm{cm})$ & $172 \pm 7$ & $170 \pm 7$ \\
Weight $(\mathrm{kg})$ & $81 \pm 13$ & $80 \pm 11$ \\
Years on job & $15 \pm 9$ & $11 \pm 11$ \\
Smoked: & $13 \%$ & $7 \%$ \\
$\quad$ Never & $32 \%$ & $53 \%$ \\
Previously & $55 \%$ & $40 \%$ \\
\hline Currently & & \\
\hline
\end{tabular}

*Mean \pm standard deviation. 
Table 2 Respirable and non-respirable dust levels obtained by personal dust monitoring of grain handlers

\begin{tabular}{llll}
\hline & $\begin{array}{l}\text { No of } \\
\text { subjects }\end{array}$ & $\begin{array}{l}\text { Respirable dust } \\
\left(\mathrm{mg} / \mathrm{m}^{3} \text { of air) }\right.\end{array}$ & $\begin{array}{l}\text { Non-respirable dust } \\
\left(\mathrm{mg} / \mathrm{m}^{3} \text { of air) }\right.\end{array}$ \\
\hline Monday & 35 & $0.9 \pm 0.7 \dagger$ & $4.3 \pm 8.5$ \\
Tuesday & 45 & $1.3 \pm 1.5$ & $8.6 \pm 15.2$ \\
Wednesday & 46 & $0.8 \pm 0.7$ & $4.9 \pm 10.2$ \\
Thursday & 47 & $0.9 \pm 1.1$ & $5.6 \pm 12.9$ \\
Friday & 35 & $0.6 \pm 0.4$ & $3.0 \pm 5.2$ \\
Average* & 47 & $0.9 \pm 0.7$ & $5.7 \pm 10.9$
\end{tabular}

${ }^{*}$ Average of weekly means for all subjects.

† Mean \pm standard deviation.

\section{PULMONARY FUNCTION CHANGES}

The following analysis is based on 34 of the 47 grain handlers who had a complete set of pulmonary function results available at the beginning and the end of all work shifts on Mondays, Wednesdays, and Fridays, consisting of the FVC, FEV,$\dot{V} \max _{50 \% v c}$, and $\dot{V} \max _{25 \% \mathrm{VC}}$. The incomplete data sets occurred randomly in time and were explained either by the subjects being unable to report for the tests or to a given set of results being rejected on technical grounds. The subjects having complete results did not differ from those deleted in the characteristics listed in table 1 .

Within-day and between-day comparisons were made for each of the pulmonary function variables (table 3). The FVC decreased from Monday to Wednesday and this change was sustained on Friday. The morning and afternoon FVC measurements did not differ on any day. The FEV, decreased from Monday morning and afternoon to the respective times on Wednesday, but increased every afternoon compared with the morning of the same day. The $\mathrm{FEV}_{1} / \mathrm{FVC}$ ratio followed the same pattern. The $\dot{V} \max _{50 \% \mathrm{vc}}$ decreased progressively at each test period until Friday afternoon; the value on Friday afternoon was higher than on the morning of the same day but remained appreciably lower than the Monday morning value. The $\dot{V} \max _{25 \% v c}$ behaved in a similar manner to the $\dot{V} \max _{50 \% \text { vc }}$

These within-day decreases in the flow rates on Mondays and Wednesdays were indicative of an obstructive ventilatory defect. The within-week decrease in the FVC, however, could technically be explained by either pulmonary obstruction with gas trapping or restriction. The corresponding subdivisions of lung volume measured independently by the helium dilution method were available for 30 subjects on Monday mornings and Friday afternoons. All of these subjects also had full flow volume curve data at both times, which showed the same changes as those in table 3 . These workers showed a small but significant decrease in their TLC from Monday morning to Friday afternoon (115 \pm 16 to $112 \pm$ $16 \%$ of predicted, average \pm standard deviation; $p$ $=0.05)$ and a similar trend in their FRC (108 \pm 27 to $105 \pm 24)$, and $\operatorname{RV}(113 \pm 39$ to $110 \pm 34)$, with the $R V / T L C$ ratio remaining constant. Thus these findings suggested that a restrictive ventilatory defect was present in addition to the airway obstruction.

The FVC of the 15 civic workers examined in 1977 did not change from Monday to Friday morning (111 \pm 13 to $111 \pm 12 \%$ of predicted, average \pm standard deviation). The $\mathrm{FEV}_{1}$, and flow rates decreased to a small degree (113 \pm 19 to $110 \pm 20$ for the $\mathrm{FEV}_{1}, 123 \pm 30$ to $114 \pm 24$ with $\mathrm{p}=0.03$ for the $\dot{V} \max _{50 \% v c}$ and $76 \pm 31$ to $68 \pm 28$ with $\mathrm{p}=$ 0.05 for the $\left.V \max _{25 \% \mathrm{vc}}\right)$. There were small associated increases in the FRC $(82 \pm 16$ to $85 \pm 15)$, TLC (96 \pm 14 to $99 \pm 8)$, and RV (76 \pm 23 to $79 \pm$ 18). Only the change in the flow rates was statistically significant. These findings indicated that the civic workers developed within-week changes of slight airway obstruction, but there was no associated restrictive defect.

Table 3 Pulmonary function of 34 grain handlers* at the beginning and end of work shifts on alternate days of a given week

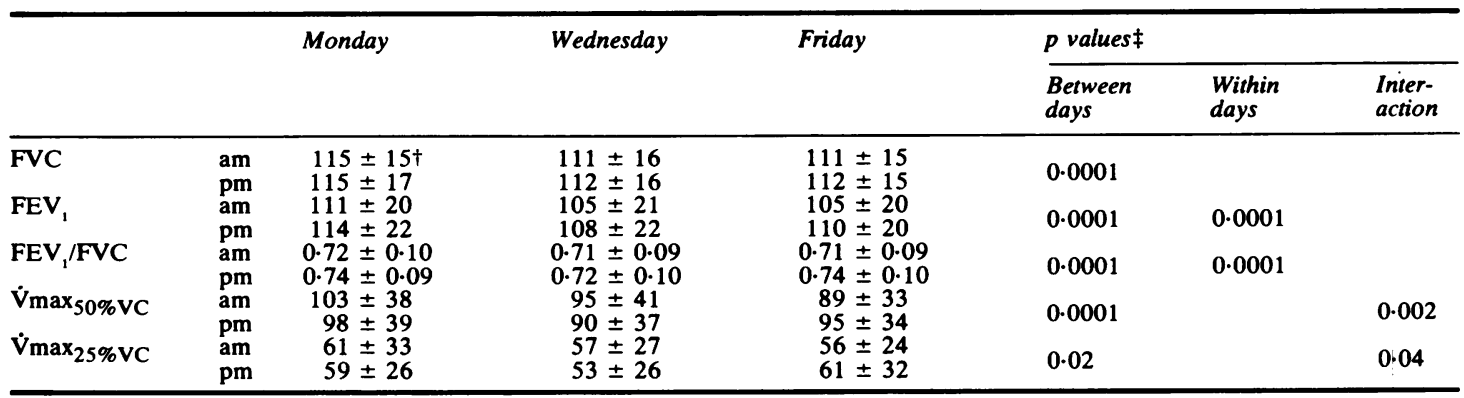

*All subjects have complete data at each point in time.

†Percentage of predicted values, mean \pm standard deviation.

$\ddagger p$ values obtained by analysis of variance. A blank value indicates a probability $>0.05$. 
The change in the FVC and FEV, of the civic workers from Monday to Friday morning were significantly smaller than those of the grain handlers; both comparisons yielded a $p$ value of less than $0 \cdot 05$. The comparison of the corresponding changes in the flow rates of the grain and civic workers were not significantly different.

\section{DOSE-EFFECT RELATIONSHIPS}

We examined two different aspects of the relationship between pulmonary function and dust exposure, using the data obtained in the grain handlers. The first was concerned with the correlation between the baseline pulmonary function of the grain workers and their usual dust exposure. The assumption was made in this analysis that the baseline pulmonary function of each subject was reasonably represented by his Monday morning pulmonary function measurements. Similarly, the mean dust exposure of each subject during the week of his study was taken as representative of his usual dust exposure. The second aspect of our interest was concerned with the acute daily effect of grain dust exposure. This was studied by determining the relationship between the daily changes in pulmonary function of each subject and his personal exposure to dust on the same day.

The requirements for inclusion of subjects in analyses relating to the first objective consisted of the availability of flow volume curve and lung volume data on Monday mornings along with dust measurements on Tuesdays, Wednesdays, and Thursdays. Only these three days were used for estimating the usual dust exposure of a given subject, since several measurements were missing for Mondays or Fridays. These criteria were all satisfied by 36 of the grain handlers. For the second objective we required only the flow volume curve data from the beginning and end of a minimum of two work shifts for a given subject. Again, matching measurements of dust exposure were needed on the same days. These criteria were satisfied by 39 workers, of whom 20 had complete data for two shifts and 19 for three shifts.

Masks were worn for up to several hours daily by roughly half of the subjects (table 4). This practice was treated as a major independent variable in the following analyses in view of the obvious possibility that it might influence the outcome. The subjects who wore a mask were younger and had a shorter duration both of working in an elevator and of smoking than the others. The mask-wearing group had a higher exposure to both respirable and nonrespirable dust, but did not differ from the others in their Monday morning pulmonary function results.

The relationships of dust exposure with baseline
Table 4 Characteristics of grain handlers according to practice of wearing a mask

\begin{tabular}{|c|c|c|c|}
\hline & \multicolumn{2}{|l|}{ Wear mask } & \multirow[t]{2}{*}{$p$ value $\S$} \\
\hline & $\begin{array}{l}\text { No } \\
(n=17)\end{array}$ & $\begin{array}{l}Y e s \\
(n=19)\end{array}$ & \\
\hline \multirow{12}{*}{$\begin{array}{l}\text { Age (years) } \\
\text { Duration of employment } \\
\text { (years) } \\
\text { Smoking (pack-years) } \\
\text { FVC* } \\
\text { FEV } \\
\dot{V}^{*} \text { max }_{50 \% \text { VC }} \\
\text { Vmax }_{25 \% \text { VC }} \\
\text { Functional residual } \\
\text { capacity } \\
\text { Total lung capacity } \\
\text { Residual volume } \\
\text { Respirable dust } \\
\left.\text { (mg/m }{ }^{3}\right)^{\dagger} \\
\text { Non-respirable dust }\end{array}$} & $45 \pm 12 \ddagger$ & $36 \pm 11$ & 0.02 \\
\hline & & & \\
\hline & $20 \pm 8$ & $9 \pm 6$ & 0.0001 \\
\hline & $35 \pm 23$ & $20 \pm 17$ & 0.03 \\
\hline & $120 \pm 17$ & $113 \pm 13$ & \\
\hline & $\begin{array}{l}116 \pm 20 \\
108 \pm 45\end{array}$ & $\begin{array}{l}113 \pm 16 \\
115 \pm 32\end{array}$ & \\
\hline & $64 \pm 41$ & $75 \pm 36$ & \\
\hline & & & \\
\hline & $\begin{array}{l}104 \pm 25 \\
112 \pm 20\end{array}$ & $\begin{array}{l}100 \pm 25 \\
108 \pm 12\end{array}$ & \\
\hline & $101 \pm 32$ & $109 \pm 35$ & \\
\hline & $0.66+0.26$ & $1.13+0.79$ & $00 ?$ \\
\hline & & & \\
\hline & $1.65 \pm 1.35$ & $8 \cdot 14 \pm 9 \cdot 6$ & 0.009 \\
\hline
\end{tabular}

${ }^{*}$ Baseline pulmonary function measurements made on Monday morning are expressed as percentage of age-height predicted values.

$\dagger$ Dust concentrations represent average of daily measurements for each subject made over Tuesday, Wednesday, and Thursday.

$\ddagger$ Mean \pm standard deviation.

§Probability associated with Mann-Whitney test comparing the two groups who wear and do not wear a mask. A blank $p$ value indicates a probability $>0.05$.

pulmonary function were explored by calculating all possible linear and multiple regressions using as predictor variables, age, duration of employment, pack-years of cigarette smoking, and usual exposure to respirable and non-respirable dust. Among the workers who did not wear a mask, respirable dust was inversely related to the baseline $\mathrm{FEV}_{1}$, $\dot{\mathrm{V}} \max _{50 \% \mathrm{VC}}$, and $\dot{\mathrm{V}} \max _{25 \% \mathrm{Vc}}$ (table 5). Also, packyears varied inversely with the baseline $F E V_{1} / F V C$ ratio and $\dot{V} \max _{25 \% \mathrm{Vc}}$, while duration of employment varied directly with the baseline FVC and $\mathrm{FEV}_{1}$. Among workers who wore a mask, packyears were a significant predictor of the baseline $\mathrm{FEV}_{1} / \mathrm{FVC}$ and $\operatorname{Vmax}_{25 \% \mathrm{vC}}$, in a similar manner as seen with the non-mask wearers. The only other significant relationship defined in the mask wearers indicated that the level of respirable dust varied directly with the baseline $\operatorname{V} \max _{25 \% \mathrm{Vc}}$ (coefficient 19.7, $\mathrm{p}=0.02$ ). The baseline FRC, TLC, and RV were not significantly predicted by any of the foregoing variables. Moreover, age and non-respirable dust did not appear as significant predictors of any parameter of baseline pulmonary function. Similar results were obtained when all available dust measurements were used for each subject. Also, the two dimensional plots for all of these relationships were inspected for outliers and none was found. In addition, all of the regression analyses were repeated using a more robust procedure ${ }^{15}$ that relies on the minimisation of the sum of absolute deviations rather than the sum of squared deviations as in con- 
ventional regression; these confirmed the relationships described in table 5 .

The acute effects of dust exposure were assessed by relating the daily dust measurements for a given subject with the corresponding absolute daily changes in pulmonary function. Since each subject had data for two or three days, an estimate could be made of the slope of the relationship between dust exposure and acute change in pulmonary function for all workers individually. These data yielded a negative slope when there was a direct relationship between the level of dust exposure and degree of decrease in pulmonary function.

If there were no direct acute effects of dust levels on daily change in pulmonary function we would not expect the slope to be negative for a given pulmonary function test in more than half the subjects. We tested this hypothesis using the sign test and found that roughly $70 \%$ of the slopes were negative (table 6) for the relationship between respirable dust and both the daily change in $\operatorname{Vmax}_{50 \% \mathrm{Vc}}(\mathrm{p}=0.004)$ and $\dot{V} \max _{25 \% \mathrm{Vc}}(\mathrm{p}=0.08)$. No significant increase in the number of negative slopes was found between respirable dust and the daily change in FVC and $\mathrm{FEV}_{1}$, nor for any of the relationships involving non-respirable dust. These results were confirmed using the Wilcoxon signed-rank statistic. The median of the slopes between respirable dust and both daily change in $\dot{V} \max _{50 \% \mathrm{VC}}$ and $\operatorname{Vmax}_{25 \% \mathrm{VC}}$ were significantly greater than zero $(p=0.004$ and 0.01 respectively). Similar relationships were found when the logarithms of the pre-shift and post-shift pulmonary function data were used to calculate proportional within-day changes in place of the absolute changes used above and also when the percentage of predicted changes in pulmonary function were used.

Multiple regression analysis was used to determine whether the individual slopes were related to mask-wearing, age, duration of employment, extent of smoking, and baseline pulmonary function. No significant relationships were discovered.

We attempted to define a dose-effect relationship between the pooled data for respirable dust exposure and the daily change in the flow rates. The correlation coefficient was found to be $-0.049(p=0.63)$ for the $\dot{V} \max _{50 \% \mathrm{Vc}}$ and $-0.13(\mathrm{p}=0.21)$ for the ${ }^{\prime} \max _{25 \% \mathrm{vc}}$. This inability to show a significant dose-effect relationship from the pooled data despite a majority of the individual responses having the same direction of slopes (table 6), was due to a pronounced heterogeneity among the subjects both in the levels of their flow rates and in their exposure to dust.

\section{Discussion}

Grain dust is known to be a heterogeneous material

Table 5 Multiple regression analysis relating baseline pulmonary function with certain predictor variables in 17 grain handlers who did not wear a mask

\begin{tabular}{|c|c|c|c|c|c|}
\hline & \multirow{2}{*}{$\begin{array}{l}\text { Correlation } \\
\text { coefficient }\end{array}$} & \multirow[t]{2}{*}{ Intercept } & \multicolumn{3}{|c|}{ Regression coefficients $\dagger$} \\
\hline & & & $\begin{array}{l}\text { Respirable } \\
\text { dust } \\
\left(\mathrm{mg} / \mathrm{m}^{3} \text { of } \text { air }\right)\end{array}$ & $\begin{array}{l}\text { Pack } \\
\text { years }\end{array}$ & $\begin{array}{l}\text { Employment } \\
\text { duration }\end{array}$ \\
\hline 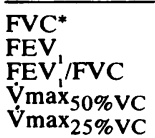 & $\begin{array}{l}0.52 \\
0.72 \\
0.67 \\
0.58 \\
0.77\end{array}$ & $\begin{array}{r}98 \\
118 \\
80 \\
174 \\
141\end{array}$ & $\begin{array}{r}-38.4(p=0.02) \\
-101.8(p=0.01) \\
-67.4(p=0.03)\end{array}$ & $\begin{array}{l}-0.2(p=0.003) \\
-0.9(p=0.01)\end{array}$ & $\begin{array}{l}1.1(\mathrm{p}=0.03) \ddagger \\
1.2(\mathrm{p}=0.03)\end{array}$ \\
\hline
\end{tabular}

*Pulmonary function data are used as percentage of normal predicted values.

†Constant by which predictor variable is multiplied in equation for deriving baseline pulmonary function.

$\ddagger$ Significance of relationship between the predictor variable and baseline pulmonary function.

Table 6 Statistical summary of the distribution of the slopes of the individual dose-response curves of 39 grain handlers for dust concentration versus daily change in pulmonary function

\begin{tabular}{|c|c|c|c|c|c|c|}
\hline & \multicolumn{3}{|c|}{ Respirable dust $v$ change in pulmonary function } & \multicolumn{3}{|c|}{ Non-respirable dust $v$ change in pulmonary function $\dagger$} \\
\hline & $\begin{array}{l}\text { \% of slopes } \\
\text { negative }\end{array}$ & $p^{*}$ & Median slope & $\begin{array}{l}\text { \% of slopes } \\
\text { negative }\end{array}$ & $p$ & Median slope \\
\hline $\begin{array}{l}\text { FVC } \\
\text { FEV }_{1} \\
\operatorname{Vmax}_{50 \% V C} \\
\dot{V}_{\max } 25 \% \mathrm{VC}\end{array}$ & $\begin{array}{l}56 \\
56 \\
74 \\
66\end{array}$ & $\begin{array}{l}0.52 \\
0.52 \\
0.004 \\
0.08\end{array}$ & $\begin{array}{l}-236 \mathrm{ml} \\
-100 \mathrm{ml} \\
-923 \mathrm{ml} / \mathrm{s} \\
-310 \mathrm{ml} / \mathrm{s}\end{array}$ & $\begin{array}{l}38 \\
44 \\
46 \\
54\end{array}$ & $\begin{array}{l}0.26 \\
0.42 \\
0.63 \\
0.75\end{array}$ & $\begin{array}{c}19 \mathrm{ml} \\
30 \mathrm{ml} \\
42 \mathrm{ml} / \mathrm{s} \\
-17 \mathrm{ml} / \mathrm{s}\end{array}$ \\
\hline
\end{tabular}

*Probability associated with sign statistic for testing hypothesis that percentage of positive slopes is not greater than $50 \%$.

† Slope could not be calculated for one subject whose non-respirable dust exposure was same on all days. 
composed of cereal grain particles, silica, fungal spores, insect parts, mites, mammalian debris, and agricultural chemicals. ${ }^{16}$ This material is considered to be a nuisance dust for which the usual threshold limit value is $10 \mathrm{mg}$ of total dust $/ \mathrm{m}^{3} .{ }^{17}$ The average dust concentrations measured in our study were considerably lower than this threshold limit value (table 2). Also, our results were moderately lower than those reported by Chan-Yeung et $a l^{2}$ and substantially lower than those described by Farant and Moore $^{18}$ and by doPico and his colleagues. ${ }^{3}$

The results of several controlled surveys have shown that grain handlers not only have an increased frequency of respiratory symptoms but also measurable differences in pulmonary function. A decrease in flow rates has been presented as evidence of airways obstruction in Montreal grain dock workers ${ }^{4}$ and in Saskatchewan grain elevator workers. ${ }^{5}$ Our survey of grain elevator workers in Thunder Bay showed a reduction in FVC and FEV, without significant differences in midflow rates, ${ }^{1}$ a finding confirmed by Chan-Yeung et al in a study of Vancouver grain handlers. ${ }^{2}$ We also found a lower $\mathrm{DL}_{\mathrm{CO}}$ in non-smoking grain handlers. Nevertheless, differences between the results of separate studies may be reconcilable, since we have shown that the results obtained in grain handlers may vary with seasonal changes in the activity of the industry. ${ }^{6}$ Also, our present report indicates that the pulmonary function of grain handlers may change according to the time of the day and the day of the week. Moreover, we also show here that changes in pulmonary function are directly related to the level of dust exposure.

\section{PULMONARY FUNCTION CHANGES}

Our results showed a morning to afternoon decrease in the $\dot{V} \max _{50 \% \mathrm{VC}}$ and $\dot{\mathrm{V}} \mathrm{max}_{25 \% \mathrm{vc}}$ of the grain handlers on Mondays and Wednesdays, without any associated decrease in FVC (table 3 ). This change clearly reflects the appearance of airway obstruction within these shifts. The rise in flow rates on Friday afternoon may possibly be related to acclimatisation.

The $F E V_{1}$ is known to show a diurnal increase during the hours of the day in which our 1977 study was conducted. ${ }^{1920} \mathrm{~A}$ similar pattern has been described with the peak expiratory flow rate ${ }^{21}$ and airway resistance has been shown to be lowest in the early afternoons. ${ }^{22}$ Nevertheless, an explanation appears to be required for our finding that the FEV increased over the course of each shift while the other flow-related variables decreased (table 3). $\mathrm{FEV}_{1}$ is influenced not only by the elastic recoil of lung and the resistance of intrapulmonary airways but also by the effort-dependent portion of a maxi- mum forced expiration. Flow (and consequently volume change) which is generated in the effortdependent portion is a function of the strength, effort, and co-ordination of the subject as well as the resistance of the airways including the larynx. ${ }^{23}$ Finally, the $\mathrm{FEV}_{1}$ will depend on the FVC, being particularly affected by a change in TLC. This latter factor is unlikely to explain the increase in FEV over a shift as no volume changes were documented (table 3). We found, however, that a correlation existed between peak expiratory flow and FEV whereas no correlation could be seen between peak flow and $\dot{V} \max _{50 \% \mathrm{vc}}$. We conclude that factors affecting the effort-dependent part of maximum forced expiration were responsible for this apparent discrepancy between the within-shift change in the $\mathrm{FEV}_{1}$ and the $\operatorname{Vmax}_{50 \% \mathrm{vC}}$ and $\operatorname{Vmax}_{25 \% \mathrm{vc}}$. The multiple factors concerned in the determination of the $\mathrm{FEV}_{1}$ suggests that cautious interpretation of change is possible where time of testing and FVC are constant.

Our results also showed a Monday to Friday decline in the FVC, and $\mathrm{FEV}_{1}, \mathrm{~V}_{\mathrm{max}} \mathrm{x}_{50 \% \mathrm{VC}}$, and V $\max _{25 \% \mathrm{VC}}$ among the grain handlers (table 3 ). Such a change in FVC has been regarded as a function of a raised $\mathrm{RV}$ presumably due to airway closure as seen in some asthmatic reactions. ${ }^{24}$ This response, however, could also be found if TLC was reduced as a result of muscle weakness or decreased compliance of the lung or chest wall.

The obstructive changes detected among the grain workers were in fact found to be associated with a significant within-week decrease in the TLC, with parallel changes in the FRC and RV. Nevertheless, this measurement was obtained by the helium dilution method, and the possibility therefore arises that the within-week decreases in lung volume were an artifact due to maldistribution of the indicator gas caused by the associated airway obstruction. This appears to be unlikely, however, since the degree of obstruction was mild and the volume measurements were made with scrupulous attention to achieving full equilibration of the helium. Moreover, the civic workers, who showed obstruction of a comparable magnitude, did not undergo any diminution of lung volume. We interpret the obstructive change in the civic workers as likely to be related to dust exposure during the course of sanitation and road work.

We examined a group of $\mathbf{2 7}$ grain handlers in a similar manner on Monday and Friday mornings, two years after the foregoing study. On this second occasion the dust concentrations were roughly $50 \%$ lower than those of 1977 , and the grain handlers did not show any significant within-week changes in pulmonary function. Ten of these subjects, however, exhibited a decrease from Monday to Friday of their 
FVC, along with their TLC measured plethysmographically, comparable with that observed in 1977. We consider the less general effect observed in 1979 to be most likely related to the lower level of dust exposure.

The single published report of within-shift and within-week variation of pulmonary function in grain handlers is that of Chan-Yeung et al, ${ }^{2}$ who showed a decrease in the FVC and in FEV, but no change in midflow rates. They attributed the lack of change in flow rates to the variability of the measurement in cortrast to the FVC and FEV the presence of obstructive disease. An alternative explanation would be the development of a restrictive abnormality.

The occurrence of a pulmonary restrictive problem caused by exposure to grain dust is not a new concept. Davies et $a^{25}$ have described an individual who, in response to bronchial challenge with grain dust, developed evidence not only of severe bronchial obstruction but also showed marked reductions in TLC and RV. They considered the phenomenon of a decrease in lung volume to be possibly due to constriction of small airways, as has been shown in animals ${ }^{26}$ but without an effect on the gas exchanging spaces. It is noteworthy, however, that the $\mathrm{KCO}$ (ratio of the carbon monoxide diffusing capacity to the total lung capacity) of their patient decreased after challenge. Similarly, if the pressure-volume curves of their patient are plotted with reference to the observed TLC rather than the observed VC, they show an increase in elastic recoil for a given lung volume.

Our study showed the appearance of airways obstruction within some day shifts (table 3 ) and also suggested the development of volume restriction during the course of a week of work. The volume restriction could occur from an insult causing constriction of small airways, since this has been shown to produce pressure-volume changes in man. ${ }^{27}$ The possibility cannot be excluded, however, that this reported volume restriction and pressure-volume change may be in part due to an effect at the alveolar level.

DOSE-EFFECT RELATIONSHIPS

Our study shows that the baseline $\mathrm{FEV}_{1}$, $\dot{V} \max _{50 \% \mathrm{VC}}$, and $\dot{\mathrm{V}} \max _{25 \% \mathrm{VC}}$ of grain handlers who did not wear a mask varied inversely with their exposure to respirable dust (table 5). These findings suggest indirectly that although the flow rates tend to improve on Friday (table 3 ), there is some residual obstructive defect which persists over a weekend. The absence of an observed relationship between respirable dust exposure and the baseline lung volume measurements raises the possibility that the restrictive defect may be more reversible. These measurements, however, are also relatively variable, perhaps making this relationship more difficult to observe among the number of subjects studied.

These relationships between the baseline pulmonary function and exposure to respirable dust were not observed in subjects who wore a mask. This suggested that wearing a mask is associated with a beneficial effect, which was further supported by the observation that the $\operatorname{Vmax}_{25 \% \mathrm{vc}}$ varied directly with respirable dust among those who wore a mask. The latter may have been a result of a tendency for workers to wear a mask for increasing periods under dustier conditions. Nevertheless, this finding cannot be confidently attributed to mask wearing, since the subgroups also differed in other important respects, including age, duration of employment, and smoking (table 4).

The FVC and FEV 1 were paradoxically found to increase with longer duration of employment in those subjects who did not wear a mask (table 5). This may be related to the tendency for the most recently employed men to be given the dustiest jobs (table 4). In addition, workers who are most affected by exposure to grain dust may be inclined to relinquish their work, leaving behind a more healthy survivor population.

We also showed an acute effect of grain dust exposure that was mainly manifested by a daily decrease in $\dot{V} \max _{50 \% \mathrm{vc}}$ and $\dot{\mathrm{V}} \mathrm{max}_{25 \% \mathrm{vc}}$ in direct relation to the level of respirable dust exposure (table 6). There was no corresponding change in the FVC or FEV 1 and the effect was not clearly related to wearing a mask. Nevertheless, workers who wore a mask worked in higher dust concentrations than those who did not (table 4), raising the possibility that both subgroups may be exposed to a similar effective concentration of the component of grain dust responsible for this acute effect on the flow rates.

We attempted to define an exact dose-effect relationship between respirable dust exposure and within-day change in $\dot{V}^{\prime} x_{50 \% v c}$ or $\dot{V} \max _{25 \% \mathrm{vc}}$, by using the individual or pooled data for these variables. This was prevented in the case of the individual results, however, by the limited number of data points available for defining a curve and in the case of the pooled results by the pronounced heterogeneity of response between subjects. Nevertheless, the magnitude of this response may be estimated from the median of the slope for all of the relationships, which indicated that $50 \%$ of the subjects underwent a daily decrease in their $\dot{V} \max _{50 \% \mathrm{VC}}$ of at least $923 \mathrm{ml} / \mathrm{s}$ and in their $\dot{V} \max _{25 \% \mathrm{vc}}$ of 310 $\mathrm{ml} / \mathrm{s}$, for each $1 \mathrm{mg} / \mathrm{m}^{3}$ increase in the concentration of respirable dust (table 6). 
The effects of dust exposure on both the baseline and within-day changes in pulmonary function were observed with respirable dust but not with nonrespirable dust. This is not surprising, since we assume that the dust must gain access to the lungs in order to affect these parameters of pulmonary function, and this can occur more effectively with the material in the respirable fraction. The possibility therefore arises that air quality standards in the grain industry should be based on respirable dust. Suppression of this would also lower the nonrespirable fraction and mitigate its effects on parts of the body such as the nose, eyes, and skin.

This study was supported by a grant from Health and Welfare, Canada. We are grateful to Nicola Wachmann, Len Hong, and Jon Kuzyk for their technical help, and to Cheri Aitken and Marilyn Okada for the data management. The monitoring of dust exposure was conducted by the staff of Labour Canada. Our work was made possible by the full co-operation of the Canadian Lakehead Grain Elevator Workers, the Saskatchewan Wheat Pool, Local 87 of the Canadian Union of Public Employees, and the City of Thunder Bay.

\section{References}

' Broder I, Mintz S, Hutcheon M, et al. Comparison of respiratory variables in grain elevator workers and civic outside workers of Thunder Bay, Canada. Am Rev Respir Dis 1979;119:193203.

${ }^{2}$ Chan-Yeung M, Schulzer M, MacLean L, Dorken E, Grzybowski S. Epidemiological health survey of grain elevator workers in British Columbia. Am Rev Respir Dis 1980;121:329-38.

${ }^{3}$ doPico GA, Reddan W, Flaherty D, et al. Respiratory abnormalities among grain handlers: a clinical, physiologic, and immunologic study. Am Rev Respir Dis 1977;115:915-28.

${ }^{4}$ Becklake MR, Jodoin G, Utz G, Lefort L, Rose B, Fraser RG. A health study of grainhandlers in St Lawrence river ports (abstract). Am Rev Respir Dis 1977;115:200.

s Dosman JA, Cotton DJ, Graham BL, Li KYR, Froh F, Barnett GD. Chronic bronchitis and decreased forced expiratory flow rates in lifetime nonsmoking grain workers. Am Rev Respir Dis 1980;121:11-6.

- Broder I, Mintz S, Hutcheon MA, Corey PN, Kuzyk J. Effect of layoff and rehire on respiratory variables of grain elevator workers. Am Rev Respir Dis 1980;122:601-8.
' Goldman HI, Becklake MR. Respiratory function tests. Normal values at median altitudes and the prediction of normal results. American Review of Tuberculosis and Pulmonary Diseases 1959;79:457-67.

' Morris JF, Temple WP, Koski A. Normal values for the ratio of one-second forced expiratory volume to forced vital capacity. Am Rev Respir Dis 1973;108:1000-3.

${ }^{9}$ Lapp NL, Hyatt RE. Some factors affecting the relationship of maximal expiratory flow to lung volume in health and disease. Dis Chest 1967;51:475-81.

${ }^{10}$ Macklem PT. Procedures for standardised measurements of lung mechanics. Bethesda, Maryland: National Heart and Lung Institute, Division of Lung Disease, 1974.

"Aerosol Technology Committee, American Industrial Hygiene Association. Guide for respirable mass sampling. Am Ind Hyg Assoc J 1970;31:133-7.

${ }^{12}$ SAS User's Guide. Cary, North Carolina: SAS Institute Inc, 1979.

${ }^{13}$ Lehmann EL, D'Abrera HJM. Nonparametrics. Statistical methods based on ranks. New York: McGraw-Hill International Book Company, 1975.

14 Snedecor GW, Cochran WG. Statistical methods. 6th ed. Ames, Iowa: The Iowa State University Press, 1968.

is SAS Supplemental Library User's Guide. Cary, North Carolina: SAS Institute Inc, 1980.

${ }^{16}$ Cotton DJ, Dosman JA. Grain dust and health. III Environmental factors. Ann Intern Med 1978;89:420-1.

${ }^{17}$ American Conference of Governmental Industrial Hygienists. Threshold limit values for chemical substances and physical agents in the workroom environment with intended changes for 1980. Cincinnati: ACG IH, 1980. (0H45201.)

18 Farant J-P, Moore CF. Dust exposures in the Canadian grain industry. Am Ind Hyg Assoc J 1978;39:177-94.

19 Walford J, Lammers B, Schilling RSF, Van Der Hoven Van Gerderen D, Van Der Veen YG. Diurnal variation in ventilatory capacity. An epidemiological study of cotton and other factory workers employed on shift work. $\mathrm{Br} J$ Ind Med 1966;23:142-8.

${ }^{20}$ Lewinsohn HC, Capel LH, Smart J. Changes in forced expiratory volumes through the day. $\mathrm{Br}$ Med J 1960;i:462-4.

${ }^{21}$ Hetzel MR, Clark TJH. Comparison of normal and asthmatic circadian rhythms in peak expiratory flow rate. Thorax 1980;35:732-8.

${ }^{22}$ Kerr HD. Diurnal variation of respiratory function independent of air quality. Arch Environ Health 1973;26:144-52.

${ }^{23}$ Macklem PT, Mead J. The physiological basis of common pulmonary function tests. Arch Environ Health 1967;14:5-9.

24 Warren P, Cherniack RM, Tse KS. Hypersensitivity reactions to grain dust. J Allergy Clin Immunol 1974;53:139-49.

${ }^{25}$ Davies RL, Green M, Schofield NMcC. Recurrent nocturnal asthma after exposure to grain dust. Am Rev Respir Dis 1976;114:1011-20.

${ }^{26}$ Woolcock AJ, Macklem PJ, Hogg JC, et al. Effect of vagal stimulation on central and peripheral airways in dogs. J Appl Physiol 1969;26:806-13.

${ }^{27}$ Michaels R, Sigurdson M, Thurlbeck S, Cherniack R. Elastic recoil of the lung in cigarette smokers: the effect of nebulized bronchodilator and cessation of smoking. Am Rev Respir Dis 1979;119:707-16. 